\title{
Serial Murders
}

\author{
YURII M. ANTONYAN \\ All-Russian Research Institute of the Ministry of Internal Affairs of the Russian \\ Federation, Moscow, Russian Federation \\ ORCID: https://orcid.org/0000-0002-0030-3031, e-mail: antonyan@yandex.ru
}

\begin{abstract}
Introduction: the article is devoted to very dangerous crimes that can be both sexual and non-sexual in nature. It provides key characteristics of serial killers, especially sexual ones, and discloses their criminal behavior. Purpose: uncovering of internal causes of such offenses through criminals' motivation and external contributing factors. Consideration of motivation is reasonable, as motives contain motivating forces of behavior, its personal meaning, i.e. what these criminal actions are committed for, what is their subjective benefit for the individual. Discussion: rapes and murders committed with extreme cruelty, violence against children and causing them serious injuries, various kinds of sexual perversions have always caused natural disgust, and consequently, unwillingness to engage in direct study of the identity of offenders. The article is based on the study of personality and behavior carried out by the author himself. Results the author identifies main features defining the specifics of serial murders, such as frequency of committing crimes; cliched nature of criminal acts; crime commission in conditions of non-obviousness; manifestation of a special externally unmotivated cruelty. The researcher classifies causes of serial murders, such as need for revenge; a way of self-affirmation; concealing traces of other crimes; purging humanity of immoral personalities, dishonoring the human race; psychological dependence on criminals' own behavior; connection with some religious cults.

Keywords: murder, rape, serial sexual murders, personality and causes of serial sexual murders.

12.00.08 - Criminal law and criminology; penal law.

For c it a ti o n: Antonyan Yu.M. Serial murders. Penitentiary Science, 2021, vol. 15, no. 4 (56), pp. 844-853. DOI 10.46741/2686-9764-2021-15-4-844-853.
\end{abstract}

\section{Introduction}

There are 2 main types of multiple serial murders:

- committed for sexual reasons (serial sexual murders);

- serial murders, unrelated to sexual motives and often committed by necrophiles.

The second type of serial murders is less common than the first, and mainly determined by hatred of people and necrophilic motives. On the surface, such crimes seem unmotivated or hooligan, but in fact they are neither one nor the other. Their motives are hatred of people, and all of them are characterized by necrophilia, which should be understood as a desire for the dead, a desire to make the living dead and look into that mysterious thing called death. This was true for "Bitsevsky (after the name of the park in Moscow) maniac "Pichushkin", who also tried to prove that he was not a "pichuzhka", i.e. a small bird, he was teased so much in childhood. He killed indiscriminately - men, women, children, there were about seventy of them.

The serial killer Luk'yanchuk was also a necrophile, who was an extremely disturbing personality, quite reasonably believing that his drug addiction and alcoholism were caused precisely by the fact that he was constantly waiting for trouble, although he did not know where it would come from. Socially, he was an absolutely lumpenized alcoholic, thrown out of normal communication for a long time and forever. He lived with a cohabitant (also an alcoholic and, according to him, with a mental retardation) and her mother, a disabled person of group 2 due to a broken leg, who also abused alcoholic beverages. The latter's cohabitant, Kriulin, also lived with them; he was also an accessory to mur- 
ders committed by Luk'yanchuk. Kriulin was an alcoholic, had been in prison twice and also had no permanent home. He lived by catching stray dogs and eating them (as after-bites), and selling the skins. It is not difficult to guess what he spent money for.

The first murder was committed together with Kriulin in 1994.

Each murder (and Luk'yanchuk's own explanations about it) will be considered separately.

1. On October 10, 1994, together with Kriulin, he killed an unknown man by strangling him with a rope, and Luk'yanchuk was the initiator of the murder, he also tightened the rope around the victim's neck. Kriulin helped him by holding the victim. The corpse was hidden together in a manhole, where it was discovered during the preliminary investigation.

Regarding this case, Luk'yanchuk said the following: "That day, at about 17 o'clock, I went to get vodka, and when I returned, my cohabitant Tanya told me that during my absence some guy had knocked on our window. We started drinking vodka with Kriulin and Tanya's mother. At this time, there was a knock on the door. Tanya looked through the peephole and said that the same guy who had knocked on the window came. I took a rope, Kriulin - a knife. They opened the door, Kriulin immediately hit him on the head with the handle of a knife, he did not even have time to say anything, and I still do not know what this man wanted. We took off his jacket and knocked him to the floor, I threw a rope around his neck, although the man asked him not to kill him. I suppressed him. Together with Kriulin, we threw the body into the manhole.

I had wanted to kill a man for a long time. I had not had a chance, and then he came himself (author's note: an unknown man he killed). I told Kriulin that he should be strangled, and Kriulin wanted to stab. He is an unknown person to me, he came to be killed, and he had to be killed. I wanted to sleep after it". He seemed to know that he had come for his death, that he had to be killed. In Luk'yanchuk's story, attention is drawn to the fact that he had wanted to kill a man for a long time, and he killed someone who had not done anything to him, Luk'yanchukdid not know him at all and saw him for the first time, but he had no doubt that he should be killed.

2. On December 7, 1994, Luk'yanchuk and Kriulin were drinking alcoholic beverages in the house of Luk'yanchuk's uncle, where their mutual acquaintance Losev was present. While drinking, Luk'yanchuk stabbed Losev several times in the neck, which caused him to die on the spot. Together with Kriulin, the corpse was thrown into the same sewer manhole as the body of an unknown man.

Luk'yanchuk told about this episode the following: "When they were drinking, Losev said that he was being tried. I thought he might stab me. So I grabbed a kitchen knife and stabbed Losev twice in the neck. I wanted to pierce his head, I did not seem to notice him. I was interested in his head, I did not like his head. I was angry. Then everything was unclear. I had nothing against Losev. Losev may have a kind heart, he is a good person".

3. At the end of December 1994, Luk'yanchuk, Kriulin and a brother of the murdered Losev, Anatolii Losev, were drinking again in the house of Luk'yanchuk's uncle. There was no quarrel between the drinking companions. Anatolii Losev, drunk, lay down on the sofa and fell asleep. Luk'yanchuk dragged him to the floor and killed him with 3 blows to the neck. Together with Kriulin, the corpse was dropped into the same manhole.

Luk'yanchuk gave the following explanations about this murder: "After the first murder, I carried a folding knife with me. I took him with me to defend myself from the friends of Losev, whom I killed. Anatolii did not suspect me of anything, although he talked about wanting to find his brother's killer. I do not remember well how I killed Tolik. I did not think why I was killing him. He himself is as quiet as a mouse. I do not know how to explain it".

4. On January 7, 1995, Luk'yanchuk, Kriulin and Potapov were again drinking in the house of Luk'yanchuk's uncle. Luk'yanchuk started a quarrel with Potapov and stabbed him several times in the neck. With the help of Kriulin and his uncle, he hid the corpse in the basement of the latter's house. About this crime, the killer said: "Lev (Potapov) was an uncle's neighbor, I saw a black-and-white TV-set at his house and wanted to steal it. But the TV-set broken".

In the same month, he tried to kill another drinking companion by stabbing him in the head, but he managed to escape.

First of all, Luk'yanchuk is a mentally ill person; a forensic psychiatric examination stated that he has schizophrenia. However, it is important to understand this personality and answer the question why he killed 4 people and endangered the life of the fifth person. Mental illness has definitely played a negative role here; however, not all mentally ill people commit a series of murders. 
It is not difficult to notice that Luk'yanchuk has formed delusions of persecution, he is very afraid of everything, he does not know what exactly; therefore, his fear is global in nature and, in essence, it is a fear of death. This is a necrophilic, phobic, closed, maladapted personality, exceptionally close to death; he, like Kir'yanov, on the one hand, is afraid of it, and on the other hand, irresistibly strives for it. Luk'yanchuk said: "I helped death... I am scared without evil... I listened to its calls to kill". He felt like a servant of death. Moreover, in his sick imagination it took the image of a universal and all-consuming evil, but he did not consider this evil as negative; on the contrary, judging by his stories, it does not have sinister features, he feels good and peaceful with it. Evil is "always somewhere around", and he was under its protection. He was always drawn to death, so, according to him, he strangled drunks on the street, his roommate and her mother, but then he could still control himself and for this reason did not carry a knife with him.

Lukyanchuk's words related to the first murder are especially eloquent: "The man unknown to me came to be killed. I was so excited about it, so he came to be killed". It seems that Luk'yanchuk was fulfilling his well-defined duty, or something very important and long-planned. Therefore, he could not do otherwise. It looks like as if it was necessary for him, prescribed for him. And the unknown man remained unknown to the investigation and the court, as they buried him without finding any documents with him. After all, Luk'yanchuk believed, he had come to be killed, and documents were not needed for this. The killer did not ask himself an extra question about who he was; the main thing was "he had to be killed". The unfortunate man had no other reason to come, except to be killed.

What is evil in the understanding, or rather, in the presentiments, of Luk'yanchuk? He himself could not (or did not want to) give a definition. Apparently, this is some kind of psychologically helping force or, most likely, death itself. In any case, it is something that goes beyond his personality and at the same time is found within its framework. Luk'yanchuk himself takes a very similar position - he is both in this and that life. Life outside the womb, i.e. "ordinary" life, is death for him, and life itself can only be in the womb, i.e. before birth, the ideal place for him is only in the mother's womb. A prison cell, providing security and comfort, fulfills the functions of this womb. He feels true joy and elation when he learns about murders and other criminal facts, thus it can be assumed that it is the death of another (or others) that exhilarates him. This is a very significant circumstance, indicating that Luk'yanchuk is a necrophilic person living in his own special world between life and death.

Without knowing sexual assault perpetrator's psychology, it is impossible to understand why he did it. It leads to the presence of many criminological, forensic, expert, correctional and other problems and the almost complete absence of scientifically based proposals and recommendations for the prevention and detection of these crimes and the correction of perpetrators. There is another circumstance hindering deep research in sexual offenses: besides special knowledge and skills required for the study, such offenses themselves, due to their nature and the severity of the consequences, often repel researchers. Rapes and murders committed with extreme cruelty, violence against children and causing them serious injuries, various kinds of sexual perversions have always caused natural disgust, and consequently, unwillingness to engage in direct study of the identity of those responsible for such heinous atrocities.

It is appropriate to note that sexual behavior, albeit criminal, as well as sexual life of a person as a whole, are among the biggest and most mysterious secrets of nature, society and personality. Perhaps, it is this sphere of life, where natural and social forces are so complex and closely intertwined in a person. Sexual emotions, experiences and attitudes are purely intimate, secretive and deep, sometimes dramatic, have exceptional existential significance. They have a huge impact on person's fate, sometimes abruptly change it and affect life perception.

Sexual relations are invisibly intertwined with other relations and values, these relationships are often incomprehensible and even inexplicable to a stranger, their cognition is significantly hindered by millennial mistakes and misconceptions, fears and prejudices, biased and ambiguous assessments, superstitions and complex symbolism. Too often, intersex relationships and emotions have been considered as the source and essence of human depravity, and attitudes to them ranged from nudity and cynicism to puritanical modesty, silence and even complete denial. Nevertheless, sex and sexual relations in all their diversity always retain their powerful attractive force. As a study object, they have always attracted the attention of philosophers, psychologists, lawyers, and writers. 
Sexual violence as a kind of sexual behavior, more precisely, as its unsocialized, vandalistic form, cannot be adequately disclosed only as a legal phenomenon outside the broad context of people's sexual life, various socio-psychological connections and mechanisms, the role of sexuality in their life.

The research is aimed at uncovering internal causes of these offenses through their motivation and external contributing factors. Consideration of motivation is reasonable, as motives contain motivating forces of behavior, its personal meaning, i.e. what these criminal actions are committed for, what is their subjective benefit for the individual. After all, for an outside observer the coming consequences in the form of criminal punishment immeasurably exceed all visible benefits from the offense committed, and therefore there may be no point in committing crimes. However, it only seems so, because the wildest, vile, even ridiculous actions always have their own internal logic, their own internal justification, their own psychological gain. But this can be understood only by taking into account the motives of behavior.

Multi-episode sexual murders pose an audacious challenge to civilization. The reason for society's sharp reaction to them is their greater frequency in recent years, their extremely dangerous consequences, a lot of victims, including children, the police's helplessness in some cases. It should be noted that similar phenomena are observed all over the world, and it can be argued that the problems arising in this regard are relevant for many countries.

Sexual murderers, like primitive hunters, usually hunt down the victim, suddenly attack it, bringing it into a state of shock, rape, inflict a lot of bodily injuries with exceptional frenzy, rip open the chest and abdomen, turn out the insides, commit sexual abuse, cut off individual pieces of the body, etc. These bloody atrocities amaze with their unusual, incredible cruelty, relentlessness and cynicism of murderers and the number of victims, among whom there are many children. It seems that previously unseen monsters, formidable servants of death, who are not aware of any social institutions and human feelings, have burst into the light. This impression is further strengthened when the facts of cannibalism and eating of individual body parts of victims are revealed.

Undoubtedly, it is arduous to prevent and investigate such crimes, as they are often committed by people who have never attracted attention of law enforcement agencies and do not stand out among others. It is often difficult to decide on the number of murderers. Sometimes these crimes are committed on the territory of different regions with little evidence and without eyewitnesses.

The study shows that the so-called multi-episode (serial) sexual murders include, in addition to actual murders by inflicting bodily injuries, such actions as rape, sodomy with violence, imission (penis insertion) and introduction of various objects into all natural orifices of the body (more often into the genitals), exposure of murdered victims, masturbation against the background of contemplation of corpses, coital and oral-anal actions with corpses, cutting off the genitals and (or) mammary glands, introduction of severed male genitals into natural orifices of the victim's body, extraction of internal organs using various piercing and cutting objects and (or) by gnawing or pulling out without the use of the above-mentioned means, dismemberment of corpses, defloration (deprivation of virginity), infliction of bodily injuries of varying severity in order to obtain sexual and other satisfaction, as well as some other similar actions.

Murders defined as serial sexual are characterized by two or more facts of deprivation of life in connection with sexual experiences of the offender. At the same time, it is not important, who became a victim and what time intervals are observed between individual criminal assaults, as well as whether they are committed by a sane or insane person.

Meanwhile, sexual murders are far from homogeneous. Most of these murders are sexually motivated. This is deprivation of life in order to obtain sexual satisfaction from the fact itself, or in connection with difficult experiences of their sexual problems, the need for revenge on women, offenders' assertion as males, etc. Another part of such murders is committed solely for the purpose of rape. In this case, criminals do not get any satisfaction from the murder itself; moreover, it is quite possible that the murder is not even part of their plans, and it is possible that they regret the death of their victims. This group, of course, includes murders for the purpose of copulation with a corpse: such acts constitute a special kind of bloody crimes. R. Kraft-Ebing, introducing a concept of necrophilia, attributed such crimes to it.

Another group of so-called serial sexual murders is committed in order to hide traces of rape or other sexual acts. It is this part of the crimes that is accompanied by attempts to bury and burn victims' corpses, as well as acts of dis- 
memberment in order to conceal the previous crime. In such cases, criminals, like all those who commit serial murders for sexual motives and for the purpose of copulation with a corpse, have more or less pronounced features characteristic of necrophiles.

Attention is also drawn to those sexual murders that are committed in cases where the perpetrator regards certain words or actions of a woman as extremely humiliating for himself. This usually happens after sexual intercourse or immediately after it, while it is not necessary that this act was violent, or there was any insult. Such crimes take place only for sexual reasons, since the criminal painfully perceives victim's words precisely in relation to his sexual capabilities. He protects himself as a male.

This kind of protective murders may not be serial, but they still need to be classified as sexual.

A significant group of serial sexual murders are those that are allegedly committed to purify society from immoral personalities that disgrace mankind, dirty and unnecessary. Here the victims are prostitutes and those women who, in the killer's opinion, lead an immoral lifestyle. Such were, according to the ideas of the Irkutsk maniac Popkov, those women who drink alcoholic beverages. He killed 81 such women. The question arises whether such acts are sexual, because even the criminal himself defines his goal as society purification. Popkov also perceived this goal, that is why he claimed that he had no need to repent; in other words, he had done the right thing for society, especially since his actions had not been related to rape or sexual necrophilia, i.e. entering into an intimate relationship with a female corpse. Apparently, he convinced himself of such "noble thoughts".

First of all, the murderer's explanations cannot be trusted in any case, because a natural question immediately arises: why society gets rid of only bad women, and not men, among whom there are more than enough disgusting personalities. The versions of criminals themselves should not be trusted for the reason that they try to justify themselves in this way, including, possibly, in their own eyes. Meanwhile, the study of such sexual killers shows that they took revenge on women for their own sexual failures, for their inability to build relationships with them at the proper level. Gradually, a sexual loser develops a special psychological, partly unconscious attitude of a woman's guilt and, in this regard, self-justification, which he really needs.
It should be noted that not only sexual criminal acts can be serial. There is theft, embezzlement, fraud and other crimes. But we always pay particular attention to sexual ones, even if they are not murders, but only rapes. This happens primarily because a person's sexual life is a special, mysterious and exciting sphere of human existence. Very often, a serial criminal, the same pickpocket or fraudster, becomes psychologically dependent on his own behavior. But these non-sexual criminals are not called maniacs, only serial sexual ones are referred to such. This happens, in our opinion, precisely because of special importance of the sexual sphere in our lives. Here the biological factor is especially noticeable, it is also significant in sexual failures of men. Transferring one's guilt for sexual failures to a woman (women) is quite natural, since it allows a man to preserve his manhood, his honor as a male and thus ensure self-acceptance: after all, a person strives to accept himself only in a certain capacity. Failures here are especially painful for him.

Thus, it can be concluded that multi-episode sexual murders conditionally fall into five separate groups: 1) murders committed in order to obtain sexual satisfaction during its commission; 2) murders in order to suppress the victim's resistance before or during rape; 3) murders for the purpose of copulation with a corpse; 4) murders in order to conceal traces of the crime; 5 ) murders committed in response to actions regarded as humiliation; 6 ) revenge on a woman for murderer's own sexual failures.

Other typologies of serial sexual murders have also been proposed in science. So, G.B. Deryagin highlights the following:

1) murder as a consequence of overcoming victim's resistance during an attempted rape;

2) murder in order to deprive a victim of the opportunity to call for help;

3) murder in order to aggravate voluptuous, sexual experiences (voluptuous murder);

4) murder at the moment of uncontrolled orgasm experience (which must be distinguished from the one mentioned above);

5) murder of a victim (and witnesses) to conceal a sexual crime;

6) murder for other reasons, resembling sexual murder, but not being such [1].

It seems that this typology is not complete enough. In addition, it is not clear why murders that are not sexual in nature should be attributed to sexual murders for other motives.

Relying on literary sources, G.B. Deryagin notes that the number of murders with initially 
sexual motivation around the world has been constantly increasing for the last three decades. At the same time, they are often characterized by their serial nature, i.e. the fact that the number of criminal episodes with the murder of people reaches two or more. Etymologically a series (from the Latin series "sequence") is understood as a sequence, a group of some events that are similar, have a common feature and one name. Thus, a series of murders should be distinguished from a double or mass murder, especially since the latter, as a rule, is characteristic of criminal handwriting of the killer. The age of sexual murderers tends to decrease, and sexual murders themselves tend to become more complicated. Thus, scientific literature describes a case of sexual murder committed by a 13-year-old boy who had a dysfunctional family and psychological and psychiatric problems. He committed a murder in the process of sexual violence, repeating episodes of the erotic film he had just watched.

Similar murders in similar situations have been noted by other authors. Cases of ritual sexual violence associated with some religious cults are described.

One of the starting positions of the research conducted by the author is the recognition that rape and sexual murder are varieties of sexual behavior, more precisely, its unsocialized and most dangerous forms. Such crimes cannot be explained only as legal phenomena, outside the broad context of a person's sexual life, various individual psychological and socio-psychological connections and mechanisms, sexual drives and needs. So, we considered achievements of various sciences and tried to penetrate into the unconscious sphere of the psyche. In general, this is a criminological, one might say, criminological-psychological-psychiatric study.

The degree of protection of people from a sexual assault is still completely insufficient. Meanwhile, any crime of such type is an attack on society and its morality, and therefore public opinion as a whole has an extremely negative attitude to such encroachments and always demands severe punishment of criminals. The facts of rape of children and adolescents of both sexes, rape of women accompanied by their murder or infliction of grievous bodily harm are especially intolerable, especially in cases where such acts are committed not once, but many times. Multi-episode serial murders and rapes always cause a wide resonance; however, numerous articles and even books have very few serious attempts to understand why it happened, what pushed this particular person to such a bloody atrocity.

All the studied sexual crimes were committed in different places, under different circumstances, had different numbers of victims and were carried out in different ways. However, it is possible to find some common features, particularly, almost all of them were committed in conditions of non-obviousness, almost all the murders were accompanied by apparently unmotivated cruelty and sometimes, though rarely, two or more people became victims of these murderers. Murders were committed both in cities and in rural areas.

As for cities, a considerable part of crimes was committed in premises $(40.6 \%$ of the urban sexual murders). As a rule, such murders in the premises were preceded by a preliminary acquaintance of murderers and victims, followed by drinking alcoholic beverages together. Sometimes victims were brought to the criminal's apartment by force or under the influence of threats. In addition to the places of residence of criminals and victims, these bloody acts were also committed in city apartments belonging to their relatives or acquaintances. The rest of these crimes were committed in attics, basements, entrances of residential buildings and various institutions and enterprises, victims or criminals' places of work, hotels, and baths.

These murders were perpetrated not only in the above mentioned places. A considerable part of them (59.4\%) occurred outside any premises. These include city streets, stadiums, parks, construction sites, territories of enterprises and institutions, urban forest belts and woodlands, wastelands, remote and deserted places, territories adjacent to city railway stations and bus stations.

It is relatively easier for the criminal to commit a crime due to the almost complete absence of possible witnesses and better possibilities to hide traces of the crime there. Sometimes the murderer does not even conceal the crime committed if his residence or work is not connected in any way with this place.

It should be noted that victims were not always completely unfamiliar women. They often became those with whom the criminal had met some time before. So, the serial killer Chikatilo (53 victims) made acquaintances at railway and bus stations, at markets, and then, under a plausible pretext, took him to a deserted place. He was a good psychologist and almost unmistakably guessed lonely women, short-sighted and simple-minded. 
If we consider separately murders committed in the premises, then most of them were in the apartments of criminals (17.3\%), in the apartments of victims (11.3\%), as well as their relatives and acquaintances (3.8\%). Obviously, it is worth mentioning that in these cases they were previously acquainted, and the perpetrator did not arouse special suspicion in the victim, or due to various circumstances, for example, young age, the victim was unable to correctly assess the danger threatening her. The proportion of other urban premises chosen as the place of commission of these crimes in comparison with the places of residence of criminals and victims is relatively small. As a rule, these were isolated cases, with the exception of attics, basements and entrances of residential buildings, here their number is slightly higher (3.0\%).

As already noted, most urban serial sexual murders were carried out outside any premises (59.4\%). The share of crimes perpetrated in woodlands and forest belts is the highest (13.5\%). A few fewer of them was committed on the streets of cities (12\%). Then there were wastelands and remote deserted places $(10.5 \%)$ and urban parks (6.8\%). Murders committed at stadiums (3.0\%), construction sites (3.0\%), territories of various enterprises and institutions (5.3\%), near railway stations and bus stations $(5.3 \%)$ were less widespread.

The rates of multi-episode sexual murders in rural areas $(42.1 \%$ of the total number were committed there) are about the same as in urban conditions, but with some distinctive features. Due to rural infrastructure specifics, murders were committed in the following places: a victim's house (18.6\%), a criminal's country house $(1.0 \%)$, criminal's workplace $(7.2 \%)$, a territory of agro-industrial complexes (1.0\%), within the boundaries of settlements (8.3\%), roads and adjacent territories (6.2\%), open agricultural lands and spaces (15.5\%), woodlands and forest belts (40.2\%). Just like urban, rural murders can be conditionally divided into those committed indoors and outdoors with regard to the fact that in rural areas the place of residence and place of work often coincide.

The majority of sexual murders in rural areas were in woodlands and forest belts, followed by houses belonging to victims, open agricultural lands and spaces, places located within the boundaries of settlements, roads and adjacent territories.

If we take all serial sexual murders in urban and rural areas, then about 9\% of them were committed by association.
Some serial sex killers prepare special rooms to commit crimes, although the first attacks were in other places.

Most serial sexual murders were characterized by the use of particularly painful methods of committing crimes, cold-blooded completion of criminal intentions, mockery of victims, cynical actions, and this especially distinguishes these offenses from other serious assaults on a person. Most often multiple stab and chopped injuries were inflicted, including with specially prepared and manufactured objects; in many cases there was amputation of genitals and other body parts, autopsy of the body, insertion of various objects into natural holes, dismemberment of corpses, and in some cases, their burning or attempts to burn. A considerable number of criminals inflicted numerous punches and kicks to victims with extreme cruelty.

There were also actions aimed at facilitating the implementation of criminal intentions and removing obstacles to causing special suffering to victims. The examples of these crimes, accompanied by extreme cruelty, include such acts as thermal influence on victims' bodies and infliction of very painful sensations with piercing objects without serious bodily assault. Such cruelty of murders was also manifested in such a purely specific act as the introduction of various objects into natural openings of the body, mainly into the vagina.

As for killing methods when committing multiple murders for sexual reasons, it is necessary to note the following. The vast majority of murders were carried out by inflicting grievous bodily harm to a victim. Then goes strangulation of victims with hands and with the help of various objects (cords, victims' clothing, bedding, etc.). A small number of murders was committed with firearms, usually hunting.

It is interesting to note that only about $25 \%$ of the criminals after the murder appropriated valuable, and sometimes not particularly valuable things of their victims. Sometimes things acted as a relic for the killer.

In this case, we observe fetishization of all criminal actions and stolen objects. Things are used as an incentive to fantasize or reminisce, which can be accompanied by masturbation and sexual satisfaction achievement.

If a criminal takes revenge on women for his suffering and humiliation or acts as a cleaner of humanity, his victims are depersonalized, they are imprinted in his psyche as one person. Therefore, he is not always able to identify the 
victims later, and therefore the fetishization of stolen items becomes all the more relevant.

By the way, the idea of purging humanity is not rear. There are cases of murders of vagrants and beggars, drunken people. The most notable cleaner is Hitler, who not only destroyed the terminally ill and insane in Germany itself, but also sought to eliminate the entire peoples, such as Jews, Slavs, Gypsies and others, whom he considered harmful, dangerous and unnecessary. There have always been improvers of the human race, even in ancient times, and these are the most dangerous enemies of humanity.

It should also be noted that the criminal actions themselves are stereotyped, especially since they are serial. Stereotyping is manifested in the motives of behavior, methods of attack and actions preceding it, including in preparation for it. It is also reflected in choosing the time and place of the crime, specific sadistic actions, handling a corpse, for example, section of genitals, eating their parts, which psychologically means possessing a woman, hiding traces of his behavior, etc.

Fetishization, depersonalization and stereotyping indicate a decrease in the arbitrariness of sexual criminal behavior, which increases with disorders of mental activity. Behavior becomes addictive, a person becomes psychologically dependent on it. Attacking a woman, the killer proves himself the domination over her, although depersonalized, but it does not matter to him. The main thing is that he is her owner and can do anything with her, especially if she is dead. Therefore, domination acquires a super-value. The latter can be found in predilections for literary and film photography of aggressive sadistic and pornographic content, hobbies in anatomy, increased interest in the structure of the female body, especially female genitals.

The issue of "seasonality" is not particularly obvious for multi-episode sexual murders. Most of them were carried out in summer months, such as July and August, and their distribution over the rest of the year is more or less uniform partly due to their commitment in closed rooms.

Multi-episode nature is one of the characteristics of serial sexual murders i. Criminals committed these crimes with varying frequency, the limits of which ranged from a few minutes to several years, caused by a variety of factors. Conditionally classifying the murders by time indicators, we can single out the following groups.
1. A series of murders committed one after the other with a break of several minutes. As a rule, these crimes are committed in urban areas mainly against children and persons with whom the offender was previously familiar.

2. A series of murders committed at intervals of several days or months and lasting about a year.

3. A series of murders lasting for a number of years with time intervals between episodes from several days to several years.

The intervals between individual sexual murders were different for different subjects. However, there are 2 distinctive features. At first murders occurred relatively rarely, then at some point their frequency increased dramatically. Such a pattern as the increase in criminal activity of sexual aggressors over time speaks of the pathological development of personality with a growth in compulsivity, irresistibility of drives. Another feature indicates the criminal's possibility to correct his pathological behavior in a certain situation. So, Chikatilo and Golovkin, knowing from the press and television about the search for a sexual killer in their area, stopped their criminal activity for a while.

So, we can identify key features that determine the specifics of serial sexual murders: there are at least 2 victims; the victims are teenagers and children of both sexes and adult women; most murders are committed with extreme cruelty; all murders are associated with sexual experiences of the perpetrator; in most cases, the victim is not specifically chosen, the person assaulted just happened to be in this place; murders are committed with different frequency, different methods and tools and it is rare when the perpetrator does not finish the crime due to circumstances beyond his control; sometimes sexual murders are accompanied by acts of cannibalism; all serial sexual murders are committed in conditions of non-obviousness.

Since the murders under consideration are a kind of sexual murders, it is necessary to give a general definition of the latter. Sexual murders are all cases of unlawful deprivation of life that are associated with sexual experiences, sexual drives or motives, even if there is a disorder of drives, and relations between the sexes in a broad sense.

Thus, sexual murders include those that may not be accompanied by actual sexual acts, for example, rape, but in their inner content and subjective meaning are connected precisely with the perpetrator's sexual life, and even 
more broadly with his relations with representatives of the other sex. Most often, the analyzed crimes are committed by sexual losers, including impotents, and they all blame women for this. Psychologically, women are depersonalized.

Among sexual murderers who commit particularly brutal crimes, it is possible to single out those whose criminal actions are characterized by the suddenness of a massive affective explosion. The victim is inflicted a lot of bodily injuries for a more or less long time. Extreme cruelty, first of all, is indicated by the nature of injuries, their multiplicity. Murder is not necessarily the goal, although this most often happens; sexual motivation grows on the basis of very dramatic feelings of sexual inferiority.

At the scene of accidents, it is often possible to find traces of hands and feet, transport, blood, semen, saliva (expectoration and other body products) on the method of murder and its tools. There may be traces of drinking alcoholic beverages, pieces (scraps) of clothing, shoes, torn buttons, cigarette butts, and hair. It is necessary to properly assess broken branches of shrubs and crumpled grass, if the incident took place outside a residential building, and furniture, if inside.

In rare cases, a criminal leaves inscriptions addressed to the police at the scene of the incident. This suggests that he enters into a game with them, like "Cossacks and robbers", "Policemen and thieves". Sometimes such inscriptions indicate that a criminal is tired of hiding and wants to be caught.

Some serial sexual murders are striking with their super-savage sadistic character.

Starting from the mid-1980s, corpses of boys aged 10-15 years with traces of brutal torture and wounds in the genital area were found in the forests near Moscow, some of these organs were cut off and the corpses were dismembered. As it was established a few years later, these exceptional acts of inhumanity had been committed by a certain Golovkin, with a higher veterinary education. He was 25 years old when he killed for the first time. He was called "Udav" ("boa"), and with the help of journalists, this nickname stuck to him.

In 1982, Golovkin first tried to kill a 14-15-yearold boy in the forest. He repeated such unsuccessful attempts twice in 1986: he cut the boy's throat, committed sexual acts with him. He killed the second child by hanging him from a tree, cut off the penis with the scrotum, cut the chest to the pubis, then cut off the head, took it and the genitals with him. This sexual maniac and sadist inflicted 35 stab wounds on the other boy; he hang the other 10-year-old boy by the neck in his garage on a bracket, then took the corpse into the forest and dismembered it there, cutting off his arms, legs, and head. Later, especially for the murders, he dug a cellar in the garage, in which he completely concreted the floor, lined the walls with concrete slabs, drove a ladder into the ceiling, firmly reinforced rings, staples, and made lighting. Golovkin hanged one of his victims in the basement after committing acts of sodomy, then dismembered the body, drained the blood into the bath, amputated the penis with testicles, tried to eat meat cut off from the thigh. In approximately the same way, he committed a number of other murders of boys with dismemberment of bodies, cutting out entrails, skin removal, cutting off the genital organ, and tortured one unfortunate by hanging on a rack and scorching his face and pubis with a blowtorch. Once he killed two boys at once, and one in front of another, and then three at once - also in front of others: he tortured them, killed them for a long time and painfully, trying to prolong the suffering of the dying and those who looked at him, dismembering the dead. In all cases, Golovkin performed sexual manipulations and received sexual pleasure, although orgasm did not always occur.

There should be no doubt that this is a sexual serial killer.

Serial sexual murders are mainly committed because criminals are sexual losers, suffering severe defeats when dating women and during sexual intercourse. Such was Chikatilo, who killed 53 people, but did not rape any of them, because he was a passive homosexual and an impotent. In his motivations, revenge on women can be traced quite clearly, but also, like a real sadonecrophile, getting sexual satisfaction at the sight of the suffering and torment of the victim. Sexual losers are the most characteristic figure among serial sex killers. It is worth mentioning that none of them has ever visited doctors, as seeking assistance is a powerful blow to men's self-esteem. It is known that a person can accept himself in a certain capacity.

It should be noted that serial sexual murders in our country are solved very (!) poorly. Hence, there are several dozen victims. So, it is necessary to start with emergency measures to search for missing women, and not to wait three days from the date of the statement of disappearance. 


\section{REFERENCES}

1. Deryagin G.B, et al. Kriminal'naya seksologiya [Criminal sexology]. Moscow: YuNITI-DANA, 2011. 399 p.

\section{INFORMATION ABOUT THE AUTHOR}

YURII M. ANTONYAN - Doctor of Sciences (Law), Professor, Honored Scientist of the RSFSR, Chief Researcher of the All-Russian Research Institute of the Ministry of Internal Affairs of the Russian Federation, Moscow, Russian Federation, ORCID: https://orcid.org/0000-0002-0030-3031, e-mail: antonyan@yandex.ru 